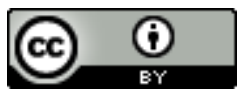

\title{
INDICADORES EDUCACIONAIS BRASILEIROS: LIMITES E PERSPECTIVAS
}

\author{
EDUCATIONAL STATISTICS IN BRAZIL: \\ LIMITS AND PERSPECTIVES \\ INDICADORES EDUCACIONALES BRASILEÑOS: \\ LÍMITES Y PERSPECTIVAS
}

\section{Taísa Grasiela Gomes Liduenha Gonçalves ${ }^{1}$ \\ Stela Cezare do Santo ${ }^{2}$ Natália Gomes dos Santos 3}

RESUMO: O presente estudo teve como objetivo analisar os dados quantitativos e apresentar algumas dificuldades e perspectivas a partir da leitura e tratamento dos dados do censo escolar da educação básica, principalmente, no que se refere à área da Educação Especial. Para tal, pautou-se em uma pesquisa documental no endereço eletrônico do Instituto Nacional de Estudos e Pesquisas Educacionais Anísio Teixeira (Inep) para verificar as relações dos indicadores educacionais com os organismos internacionais. Além disso, foram analisadas as variáveis referentes ao público-alvo da educação especial baseando-se no caderno de instruções do censo escolar da educação básica no período de 2007 a 2016. Os dados revelam que os interesses internacionais pela educação brasileira são econômicos, com estratégias para a redução da pobreza e para o aumento da produtividade por meio de um ensino aligeirado. Constatou-se uma linha tênue entre a amplitude na definição de público-alvo da educação especial e a complexidade conceitual que interfere nos dados quantitativos do censo escolar.

PALAVRAS-CHAVE: Educação especial. Indicadores educacionais. Políticas públicas de educação.

ABSTRACT: The aim of this article was to analyze the quantitative data and present some difficulties and perspectives based on the data provided by the School Census of the basic education, also focusing on the area of Special Education. To do so, a documentary research was carried out on the website of the National Institute for Educational Studies and Research "Anísio Teixeira" (Inep) to establish the connections between educational statistics and international organizations. As well, were analyzed the variables related to special education students based on the instruction manual of the school census of basic education in the period from 2007 to 2016. Data shows that such organizations have economic interests in the Brazilian education, with strategies to reduce poverty, enhance productivity, and accelerate the schooling process. It was verified a thin line between the amplification in the number of special education students and the conceptual complexity that interferes in the quantitative data of the School Census.

KEYWORDS: Special education. Educational statistics. Public policies of education.

RESUMÉN: El presente estúdio tuvo como objetivo analizar los datos cuantitativos y presentarse algunas dificultades y perspectivas a partir de la lectura y tratamiento de los datos del censo escolar de la educación básica principalmente en lo que se refiere al área de la Educación Especial. Por lo tanto, se basó en una investigación documental em el sitio electrónico del Instituto Nacional de Estudios y Investigaciones Educativas "Anísio Teixeira" (Inep) para verificar las relaciones de los indicadores educativos con los organismos internacionales. Además, se analizaron las variables referentes a los alumnos de la educación especial basándose

Submetido em: 23/08/2017 - Aceito em: 25/09/2017 - Publicado em: 14/02/2018.

\begin{tabular}{l|c|c|c|c|c|c} 
(C) Rev. Educ. Perspec. & Viçosa, $M G$ & v.8 & n.3 & p.444-461 & set./dez. 2017 & eISSN 2178-8359 \\
\hline
\end{tabular}


en el cuaderno de instrucciones del censo escolar de la educación básica en el período de 2007 a 2016. Los datos revelan que los intereses internacionales por la educación brasileña son económicos, con estrategias para la reducción de la pobreza y para el aumento de la productividad a través de una enseñanza aligerada. Se constató una línea tenue entre la amplitud en la definición de público de la educación especial y la complejidad conceptual que interfiere en los datos cuantitativos del censo escolar.

PALABRAS ClAVE: Educación especial. Indicadores educativos. Políticas públicas de educación.

\section{INTRODUÇÃO}

No período de 2010 a 2014 participou-se do projeto de pesquisa interinstitucional denominado "A escolarização de alunos com deficiência e rendimento escolar: uma análise dos indicadores educacionais em municípios brasileiros", desenvolvido pelo programa Observatório da Educação (Edital nº 38/2010/CAPES/Inep).

O objetivo do projeto interinstitucional era analisar a situação do atendimento educacional para o aluno com deficiência em municípios brasileiros, em termos de acesso, de permanência e da natureza dos serviços educacionais organizados e destinados a essa população. A base de análise comum era os microdados do censo escolar da educação básica, organizado pelo Instituto Nacional de Estudos e Pesquisas Educacionais Anísio Teixeira (Inep).

Desse modo, surgiu o interesse de compreender os indicadores educacionais e relacioná-los com as políticas públicas. Nesse contexto, o objetivo deste estudo foi analisar os indicadores educacionais e apresentar algumas dificuldades e perspectivas a partir da leitura e tratamento dos dados do censo escolar da educação básica, principalmente, no que se refere à área da Educação Especial.

O estudo se dividiu em dois momentos. No primeiro, buscou-se compreender o significado dos indicadores educacionais a partir de uma investigação no endereço eletrônico do Inep ${ }^{\mathrm{i}}$. Em seguida, foram analisadas no caderno de instruções do censo escolar da educação básica ${ }^{\text {ii }}$ as variáveis referentes ao público-alvo da educação especial no período de 2007 a 2016.

\section{INDICADORES SOCIAIS E EDUCACIONAIS}

Os indicadores sociais são dados quantitativos que possibilitam a compreensão de uma realidade concreta e se constituem como um recurso metodológico, apresentando tanto um panorama da configuração social como também as mudanças e transformações ocorridas na realidade.

\begin{tabular}{l|c|c|c|c|c|c|} 
() Rev. Educ. Perspec. & Viçosa, $M G$ & v.8 & n.3 & p.444-461 & set./dez. 2017 & eISSN 2178-8359 \\
\hline
\end{tabular}




\begin{abstract}
Os Indicadores Sociais podem ser classificados segundo as diversas aplicações a que se destinam. A classificação mais comum é a divisão dos indicadores segundo a área temática da realidade social a que se referem. Há, assim, os indicadores de saúde (percentual de crianças nascidas com peso adequado, por ex.), os indicadores educacionais (escolaridade média da população de quinze anos ou mais, por ex.), os indicadores de mercado de trabalho (rendimento médio real do trabalho, etc.), os indicadores demográficos (taxa de mortalidade, etc.), os indicadores habitacionais (densidade de moradores por domicílio, etc.), os indicadores de segurança pública e justiça (roubos a mão armada por cem mil habitantes, etc.), os indicadores de infraestrutura urbana (percentual de domicílios com esgotamento sanitário ligado à rede pública, etc.), os indicadores de renda e desigualdade (nível de pobreza, etc.). (JANNUZZI, 2002, p. 58).
\end{abstract}

O uso e desenvolvimento dos indicadores sociais estão ligados aos investimentos em planejamento da esfera pública, no século XX. Entretanto, sua consolidação, no que se refere à área científica, ocorreu na década 1960, com a finalidade de compreender as consequências das políticas sociais e suas possíveis transformações nas diferentes sociedades (JANNUZZI, 2002).

Prestam-se a subsidiar as atividades de planejamento público e a formulação de políticas sociais nas diferentes esferas de governo, possibilitam o monitoramento das condições de vida e bem-estar da população por parte do poder público e da sociedade civil e permitem o aprofundamento da investigação acadêmica sobre a mudança social e sobre os determinantes dos diferentes fenômenos sociais (JANNUZZI, 2005, p. 138).

Para a construção de um indicador social considera-se, em primeiro momento, o entendimento sobre a demanda de interesse do setor público a partir do levantamento de uma dada realidade. Isso ocorre por meio de um objetivo programático que delimitará as dimensões estabelecidas e as ações operacionais. A partir de estatísticas públicas organizadas por instituições governamentais, como o Instituto Brasileiro de Geografia e Estatística (IBGE), é possível estabelecer um acompanhamento das ações e a verificação de suas metas (JANNUZZI, 2005).

Sobre o IBGE, Jannuzzi (2002, p. 62) ressalta que "cumpre seu papel de agente coordenador do Sistema de Produção e Disseminação de Estatísticas Públicas, como produtor de dados primários, compilador de informações provenientes de ministérios e disseminador de estatísticas".

A missão institucional do IBGE é retratar o Brasil com informações necessárias ao conhecimento da sua realidade e ao exercício da cidadania, sendo o provedor de dados e informações do país, que atendem às necessidades dos mais diversos segmentos da sociedade civil, bem como dos órgãos das esferas governamentais ${ }^{\text {iii }}$.

A sistematização desses indicadores atende a recomendações internacionais e contribui para a compreensão das modificações nos perfis demográfico, social e econômico da população, possibilitando, assim, o monitoramento de políticas

\begin{tabular}{l|c|c|c|c|c|c} 
(C) Rev. Educ. Perspec. & Viçosa, $M G$ & v.8 & n.3 & p.444-461 & set./dez. 2017 & eISSN 2178-8359 \\
\hline
\end{tabular}


sociais e a disseminação de informações relevantes para toda a sociedade brasileira (IBGE, 2015, s/p).

Outro indicador educacional é o organizado pelo Instituto Nacional de Estudos e Pesquisas Educacionais Anísio Teixeira $^{\text {iv }}$, que realiza levantamentos estatísticos e avaliativos em todos os níveis e modalidades de ensino: censo escolar, censo superior, avaliação dos cursos de graduação, avaliação institucional, Sistema Nacional de Avaliação da Educação Superior, Exame Nacional do Ensino Médio (ENEM), Exame Nacional para Certificação de Competências (ENCCEJA) e Sistema Nacional de Avaliação da Educação Básica (SAEB).

O principal instrumento de coleta de informações da educação básica, que abrange as diferentes etapas e modalidades ${ }^{\mathrm{v}}$, é o censo escolar. Ele é feito com a colaboração das secretarias estaduais e municipais de educação e com a participação de todas as escolas públicas e privadas do país. Conforme a Lei de Diretrizes e Bases da Educação Nacional LDBEN (BRASIL, 1996, p. 10), §2 do artigo 9", a "União terá acesso a todos os dados e informações necessários de todos os estabelecimentos e órgãos educacionais".

O censo escolar coleta dados sobre estabelecimentos, matrículas, funções docentes, movimento e rendimento escolar. De acordo com o Inep, o censo escolar:

\footnotetext{
é uma pesquisa realizada junto aos estabelecimentos de ensino, para levantamento de dados e informações relativas à educação básica, objetivando subsidiar a elaboração de análises, diagnósticos, planejamento do sistema educacional do país e a definição e monitoramento das políticas públicas que promovam um ensino de qualidade para todos os brasileiros. Com essas informações, o MEC gerencia programas como o Fundeb, a Alimentação Escolar, a distribuição de Livros Didáticos, o Dinheiro Direto na Escola, o Mais Educação, o PDE, entre outros $(\text { BRASIL, 2012, s/p) })^{\mathrm{vi}}$.
}

Os dados do censo escolar podem ser consultados por meio do sistema Educacenso, pelo Data Escola Brasil ${ }^{\text {vii }}$, pelas sinopses estatísticas ${ }^{\text {viii }}$, pelos microdados ${ }^{\text {ix }}$ ou por solicitação direta ao Inep. Em 2015, foi divulgada a plataforma Painel Educacional, com o objetivo de apresentar informações agregadas sobre a educação das unidades da federação e dos municípios brasileiros. De acordo com o sítio eletrônico do Inep ${ }^{\mathrm{x}}$, o Painel Educacional possibilita os seguintes dados:

Trajetória: matrículas, média de estudantes por turma, estudantes incluídos, matrículas em tempo integral, taxa de aprovação, taxa de reprovação, taxa de abandono e taxa de distorção idade-série.

Contexto: indicador de nível socioeconômico, indicador de complexidade da gestão Escolar, indicador de esforço docente, indicador de adequação da formação docente, indicador de regularidade docente e indicador de desenvolvimento da Educação Básica.

Aprendizagem: participação de estudantes e escolas nas avaliações e resultados. 
As informações coletadas no censo escolar são classificadas em quatro grandes dimensões: $\operatorname{escolas}^{\mathrm{xi}}$, alunos ${ }^{\mathrm{xii}}$, profissional ${ }^{\mathrm{xii}}$ e turmas ${ }^{\mathrm{xiv}}$, e podem ser consultados por meio dos microdados. Arquivos disponíveis no site do Inep podem ser obtidos via download, em formato ASCII, e contêm inputs (canais de entrada) para leitura, utilizando os softwares Statistical Analysis System (SAS) e Statistical Package for the Social Sciences (SPSS).

Por meio dos microdados, é possível o acesso a todo o acervo coletado, a dados primários, com exceção dos dados pessoais dos alunos e profissionais escolares e dos dados cadastrais das escolas. Trabalhar os microdados da educação básica exige conhecimentos técnicos e equipamentos específicos para a manipulação e organização dos dados. Contudo, esse é o primeiro estágio da pesquisa, ou seja, "uma coisa é coletar o dado e outra é processá-lo, sistematizá-lo e difundi-lo. Outra coisa ainda é interpretá-lo" (ROSEMBERG, 2001, p. 520).

Apesar de públicos e acessíveis, os microdados do censo escolar requerem análises que "[...] dependem de boas perguntas que o pesquisador venha a fazer, ou seja, da qualidade teórica e da perspectiva epistêmica na abordagem do problema, as quais guiam as análises e as interpretações" (GATTI, 2004, p. 13).

Gatti (2004), ao realizar um estudo que consiste no levantamento dos trabalhos em educação que utilizam a abordagem quantitativa em alguns periódicos, discorre sobre diversos fatores que envolvem o uso de dados quantitativos, por exemplo, a discrição de que esses dados não sejam adotados como verdades absolutas ou dogmas, mas como possibilidade de leituras sobre o objeto de estudo em questão. Segundo a autora:

[...] os métodos quantitativos de análise são recursos para o pesquisador, o qual deve saber lidar com eles em seu contexto de reflexão (num certo sentido deve dominá-los) e, não, submeter-se cegamente a eles, entendendo que o tratamento desses dados por meio de indicadores, testes de inferência, etc. oferecem indícios sobre as questões tratadas, não verdades; que fazem aflorar semelhanças, proximidades ou plausibilidades, não certezas (GATTI, 2004, p. 14).

Ferraro (2012) nos apresenta a unidade entre qualidade e quantidade, fundamentada na perspectiva da dialética marxista. Dessa forma, compreendem-se as pesquisas qualitativa e quantitativa em um processo único, inseparável. A qualidade não existe sem a quantidade e quantidade não faz sentido sem a qualidade, ou seja, sem as perguntas necessárias, os números tornam-se meras descrições quantitativas sem uma problematização real.

Com esse panorama sobre os indicadores educacionais e o método de análise, o próximo passo é apresentar o significado dos indicadores educacionais pautando-se no endereço eletrônico do Inep. 


\section{INDICADORES EDUCACIONAIS E POLÍTICAS PÚBLICAS}

Além de subsidiar as políticas e programas voltados para a educação brasileira, os indicadores educacionais organizados pelo Inep também compõem a construção de programas e metas elaborados pelos organismos internacionais. Dentre os programas dos quais o instituto participa, encontra-se o Ines (do inglês Indicators of National Education Systems), constituinte da Organização para Cooperação e Desenvolvimento Econômico OCDE (em inglês, OECD - Organisation for Economic Co-operation and Development), que realiza, por meio de uma rígida metodologia, comparações sobre a configuração da educação de diversos países ${ }^{\mathrm{xv}}$.

Os dados do censo escolar também possuem a finalidade de ilustrar o acompanhamento das metas estabelecidas no programa "Educação para Todos", disposto pela Organização das Nações Unidas para a Educação, Ciência e Cultura (Unesco). O organismo divulga os relatórios de monitoramento, os quais apresentam os avanços e limites da educação. Em 2015, foi divulgado o último relatório, que, segundo os organizadores, “[...] oferece um relato confiável do progresso nacional e dos compromissos assumidos pela comunidade internacional, baseado em evidência estatística atualizada, em análise profunda de políticas e em estudos de caso informativos" (UNESCO, 2015, s.p., grifo nosso).

Quando se analisam os discursos dos organismos internacionais sobre a educação como direito de todos os indivíduos, devemos questionar qual educação é pensada para a classe desfavorecida e com quais interesses. Observa-se que as políticas disseminadas pelos organismos estão a serviço da manutenção social das desigualdades estabelecidas na sociedade capitalista. Segundo Dias (2012), esse quadro pode ser entendido como uma estabilização da ordem vigente, uma vez que a preservação das condições sociais atuais é de interesse da classe burguesa, de modo que, assim, é retirada da massa explorada a compreensão crítica dessa realidade. Verifica-se um jogo político apresentado pela classe dominante, a qual oferece políticas minimalistas de cunho compensatório, que exibem, em sua aparência, benefícios para os indivíduos, mas que, em sua essência, estão permeadas de concepções hegemônicas burguesas. Por estas questões os indicadores educacionais devem ser analisados para além de sua aparência, visto que as contradições encontradas no sistema interferem diretamente na configuração e dinâmica educacional (WILLIAMS, 2011).

Observa-se que tais discursos hegemônicos cooperam para a falsa impressão de superação das desigualdades sociais e políticas de oportunidades. Por esse fato, tais discursos apresentam como meta central o ensino em sua qualidade total, baseando-se na teoria do capital humano. Esses discursos humanitários são utilizados para camuflar os reais objetivos

\begin{tabular}{l|c|c|c|c|c|c|} 
(C) Rev. Educ. Perspec. & Viçosa, $M G$ & v.8 & n.3 & p.444-461 & set./dez. 2017 & eISSN 2178-8359 \\
\hline
\end{tabular}


da educação para a classe desfavorecida, os quais priorizam a formação de mão de obra para o capital (EVANGELISTA; SHIROMA, 2004).

Sendo assim, pode-se verificar que a suposta preocupação do Brasil com o desenvolvimento da educação não está atrelada ao direito dos indivíduos ao conhecimento. Sua finalidade é de cunho econômico, uma vez que:

[...] somente as nações que se adequassem aos moldes propostos por grandes agências internacionais estariam em condições de competir no mercado globalizado. Para criar o solo do consenso, muitas pesquisas e experiências educacionais foram referidas, em especial aquelas consideradas exitosas por tais agências. Os números buscavam evidenciar que o sucesso dos países centrais em termos econômicos derivava do investimento que faziam em educação. A comparação entre os índices do Produto Interno Bruto (PIB) de cada país e o percentual deste dedicado à educação oferecia dados inelutáveis de que a esse campo cabia um grande protagonismo na batalha pelo desenvolvimento (EVANGELISTA; SHIROMA, 2004, p. 03).

É nessa perspectiva que se encontram os interesses do Banco Mundial ${ }^{\mathrm{xvi}}$ em financiar a educação dos países subalternos, como o Brasil, proporcionando às nações recursos financeiros para a universalização do ensino aligeirado para as camadas populares ${ }^{\mathrm{xvii}}$. "Desta maneira, o ensino das camadas populares pode ser aligeirado até o nada, até se desfazer em mera formalidade" (SAVIANI, 2009, p. 50).

Como os demais organismos internacionais, o Banco Mundial, por meio de suas diretrizes, também exerce influência sobre as políticas e reformas educacionais dos países periféricos. Nesse viés:

[...] o Banco dedica cada vez maior atenção à construção de instituições adequadas à era do mercado, de modo a ter recursos institucionais para "manejar" as contradições do sistema. A educação é radicalmente modificada, tornando-se cada vez menos politécnica (no sentido conferido por Marx) e cada vez mais instrumental: os conteúdos estão fortemente carregados de ideologias apologéticas ao capital e o debate educacional é pautado em grande parte pelos "homens de negócios" e pelos estrategistas políticos (LEHER, 1999, p. 29, grifo do autor).

Verifica-se que é de interesse desses órgãos a elaboração das estatísticas educacionais, uma vez que elas proporcionam o acompanhamento de seus programas e metas. Desse modo, cabe à área científica o papel da análise crítica dessa configuração educacional, a qual está baseada em políticas minimalistas que não proporcionam a apropriação do conhecimento científico, mas, antes, estão a serviço dos interesses dominantes.

No que se refere à educação especial em nosso país, a história mostra a segregação, o atendimento institucional não universal e a presença maciça da filantropia (BUENO, 1993; JANNUZZI, 2006; KASSAR, 2013). 
A década de 1990 foi marcada pelas políticas inclusivas com estratégias de educação, para os países periféricos, organizadas pelo o Banco Mundial e por outros organismos, conforme explica Sanfelice (2011, p. 103):

(...) isso é pensado de forma "macro", isto é, ele indica (Banco Mundial) aos países do Terceiro Mundo em quais programas educativos devem investir, como ocorreu, por exemplo, na Conferência de Jomtien (Conferência de Jomtien - 5 a 9 de março de 1990. Declaração Mundial sobre Educação para Todos), que o Banco Mundial organizou. "Vocês têm que assinar esse acordo para cumprir essas tarefas dentro dessas condições, senão não emprestamos dinheiro para o desenvolvimento de algumas áreas". E, nesses países, há o problema do desemprego, da miséria, da fome. Então, o governo assina e começa a desenvolver os projetos. A partir desse processo, muito pouca coisa foge das lógicas do Banco Mundial e do FMI. Eles ditam as regras.

Nesse contexto, a preocupação é econômica e, segundo o Banco Mundial, a educação básica é uma estratégia para a redução da pobreza e para o aumento da produtividade. Segundo Corrêa (2004, p. 2):

(...) os organismos internacionais (responsáveis pelo patrocínio da Conferência Mundial sobre Educação para Todos) - o Programa das Nações Unidas para o Desenvolvimento (Pnud), a Organização das Nações Unidas para a Educação, a Ciência e a Cultura (UNESCO), o Fundo das Nações Unidas para a Infância (UNICEF) e o Banco Mundial, vão "pressionar" países como o Brasil, e propor o compromisso de priorização da melhoria do desempenho educacional - a "Educação para Todos", que passa a ser constituir como critério para recebimento de empréstimos internacionais.

Os dados quantitativos do censo escolar referentes à educação especial ${ }^{\text {xiii }}$ do período de 1998 a 2006 são apresentados na política nacional da educação especial na perspectiva inclusiva (BRASIL, 2008) com um acréscimo de $107 \%$ dessas matrículas na educação básica. Esse dado quantitativo mostra um avanço, se relacionado à história da educação especial. Por outro lado, o estudo de Meletti e Ribeiro (2014) revela o alto índice de evasão e repetência dos alunos com necessidades educacionais especiais matriculados na educação básica brasileira, no ano de 2012. Especificamente, há 3,19\% das matrículas em idade adequada à série; 22,67\% dos alunos apresentam defasagem de um ano; e 64,1\% ( $n=399.891$ estudantes) exibe grande defasagem (dois anos ou mais) em relação à série/ano que deveria frequentar.

Os dados quantitativos mostram que os alunos da educação especial estão chegando à educação básica. Entretanto, a maioria deles não está concretizando o processo de escolarização e o sucesso escolar. Desse modo, a análise dos indicadores educacionais pode ser pautada em interesses, sobretudo, econômicos.

Recentemente, a lei no 13.005 (BRASIL, 2014, s.p.) assegurou que "o poder público buscará ampliar o escopo das pesquisas com fins estatísticos de forma a incluir informação detalhada sobre o perfil das populações de 4 (quatro) a 17 (dezessete) anos com deficiência". Nesse

\begin{tabular}{l|l|l|l|l|l|l} 
() Rev. Educ. Perspec. & Viçosa, $M G$ & v.8 & n.3 & p.444-461 & set./dez. 2017 & eISSN 2178-8359 \\
\hline
\end{tabular}


direcionamento, o desafio dos pesquisadores da área da Educação Especial, ao apreciar os indicadores educacionais, será elaborar boas perguntas, análises e interpretações, conforme aponta Gatti (2004).

Em seguida, apresentam-se as análises referentes às variáveis do público-alvo da educação especial pautando-se no caderno de instruções do censo escolar da educação básica no período de 2007 a 2016.

\section{DESAFIOS E PERSPECTIVAS AO REALIZAR PESQUISAS COM INDICADORES EDUCACIONAIS}

Primeiramente, todo ano, ocorre o preenchimento do formulário no sistema Educacenso, via internet, por cada unidade escolar da rede pública (federal, estadual e municipal) e privada do país. As informações contidas no Educacenso sobre o rendimento e movimento escolar, somadas às avaliações do Inep, compõem o Índice de Desenvolvimento da Educação Básica (IDEB), que direciona a distribuição dos recursos para as escolas (alimentação, transporte escolar e livros didáticos) (DIAS, 2014).

O estudo de Dias (2014) sobre o preenchimento escolar, no município de Londrina, no estado do Paraná, mostra que os secretários das escolas é que realizam essa atividade, ainda que as orientações do Inep direcionem essa responsabilidade para a equipe gestora. "Segundo a Portaria $\mathrm{n}^{\mathrm{o}} 316$, de 04 de abril de 2007, é de responsabilidade dos (as) gestores (as) escolares e dirigentes dos estabelecimentos escolares públicos e privados o preenchimento das informações do Censo Escolar" (INEP/MEC, 2013, s.p.). Ainda, sobre tal responsabilidade:

\footnotetext{
As escolas e, consequentemente, os gestores das suas respectivas redes de ensino são responsáveis pela exatidão dos dados declarados e pela guarda dos documentos administrativos e pedagógicos que comprovem a matrícula e a frequência do aluno na escola (INEP/MEC, 2013, s.p.).
}

Os secretários apontaram dificuldades no preenchimento do formulário, sobretudo, no que se refere ao público-alvo da educação especial. Evidencia-se a necessidade de capacitação, pois há nomenclaturas específicas e que inferem na caracterização oficial da realidade educacional (DIAS, 2014).

A autora supracitada ressalta que os secretários apresentam muitas dúvidas ao cadastrar os alunos público-alvo da educação especial mesmo com a apresentação de um laudo médico, pois nem sempre esses laudos são claros, dificultando a interpretação e o preenchimento. Agrava-se esse problema do laudo nos casos de transtornos globais do desenvolvimento e deficiência intelectual.

\begin{tabular}{l|c|c|c|c|c|c|} 
() Rev. Educ. Perspec. & Viçosa, $M G$ & v.8 & n.3 & p.444-461 & set./dez. 2017 & eISSN 2178-8359 \\
\hline
\end{tabular}


O Quadro 1 apresenta o público-alvo da Educação Especial segundo o caderno de instruções do censo escolar da educação básica no período de 2007 a 2016. Essa delimitação ocorreu pelo fato de, no ano de 2007, a unidade básica ser o aluno ao invés da escola, como era anteriormente. O último ano analisado do censo escolar da educação básica foi o de 2016, por apresentar os dados mais atuais, no momento da realização deste estudo.

Quadro1. Público-alvo da Educação Especial segundo o censo escolar.

\begin{tabular}{|c|c|c|c|c|c|c|c|c|c|c|}
\hline Tipo & 2007 & 2008 & 2009 & 2010 & 2011 & 2012 & 2013 & 2014 & 2015 & 2016 \\
\hline Cegueira & $\mathrm{x}$ & $\mathrm{x}$ & $\mathrm{x}$ & $\mathrm{x}$ & $\mathrm{x}$ & $\mathrm{x}$ & $\mathrm{x}$ & $\mathrm{x}$ & $\mathrm{x}$ & $\mathrm{x}$ \\
\hline Baixa visão & $\mathrm{x}$ & $\mathrm{x}$ & $\mathrm{x}$ & $\mathrm{x}$ & $\mathrm{x}$ & $\mathrm{x}$ & $\mathrm{x}$ & $\mathrm{x}$ & $\mathrm{x}$ & $\mathrm{x}$ \\
\hline Surdez & $\mathrm{x}$ & $\mathrm{x}$ & $\mathrm{x}$ & $\mathrm{x}$ & $\mathrm{x}$ & $\mathrm{x}$ & $\mathrm{x}$ & $\mathrm{x}$ & $\mathrm{x}$ & $\mathrm{x}$ \\
\hline Deficiência auditiva & $\mathrm{x}$ & $\mathrm{x}$ & $\mathrm{x}$ & $\mathrm{x}$ & $\mathrm{x}$ & $\mathrm{x}$ & $\mathrm{x}$ & $\mathrm{x}$ & $\mathrm{x}$ & $\mathrm{x}$ \\
\hline Surdocegueira & $\mathrm{x}$ & $\mathrm{x}$ & $\mathrm{x}$ & $\mathrm{x}$ & $\mathrm{x}$ & $\mathrm{x}$ & $\mathrm{x}$ & $\mathrm{x}$ & $\mathrm{x}$ & $\mathrm{x}$ \\
\hline Deficiência física & $\mathrm{x}$ & $\mathrm{x}$ & $\mathrm{x}$ & $\mathrm{x}$ & $\mathrm{x}$ & $\mathrm{x}$ & $\mathrm{x}$ & $\mathrm{x}$ & $\mathrm{x}$ & $\mathrm{x}$ \\
\hline Deficiência mental & $\mathrm{x}$ & $\mathrm{x}$ & $\mathrm{x}$ & $\mathrm{x}$ & $\mathrm{X}$ & & & & & \\
\hline Deficiência intelectual & & & & & & $\mathrm{x}$ & $\mathrm{x}$ & $\mathrm{x}$ & $\mathrm{x}$ & $\mathrm{x}$ \\
\hline Síndrome de Down & $\mathrm{x}$ & $\mathrm{x}$ & & & & & & & & \\
\hline Deficiência múltipla & $\mathrm{x}$ & $\mathrm{x}$ & $\mathrm{x}$ & $\mathrm{x}$ & $\mathrm{x}$ & $\mathrm{x}$ & $\mathrm{x}$ & $\mathrm{x}$ & $\mathrm{x}$ & $\mathrm{x}$ \\
\hline $\begin{array}{l}\text { Transtornos invasivos do } \\
\text { desenvolvimento }\end{array}$ & $\mathrm{x}$ & & & & & & & & & \\
\hline $\begin{array}{l}\text { Transtornos invasivos } \\
\text { (globais) }\end{array}$ & & $\mathrm{x}$ & & & & & & & & \\
\hline $\begin{array}{l}\text { Transtorno } \\
\text { desintegrativo da infância } \\
\text { (psicose infantil) }\end{array}$ & & & $\mathrm{x}$ & $\mathrm{x}$ & $\mathrm{x}$ & & & & & \\
\hline $\begin{array}{l}\text { Transtorno } \\
\text { desintegrativo da infância }\end{array}$ & & & & & & $\mathrm{x}$ & $\mathrm{x}$ & $\mathrm{X}$ & $\mathrm{x}$ & $\mathrm{x}$ \\
\hline Autismo clássico & & & $\mathrm{x}$ & $\mathrm{x}$ & & & & & & \\
\hline Autismo infantil & & & & & $\mathrm{x}$ & $\mathrm{x}$ & $\mathrm{x}$ & $\mathrm{x}$ & $\mathrm{x}$ & $\mathrm{x}$ \\
\hline Síndrome de Asperger & & & $\mathrm{x}$ & $\mathrm{x}$ & $\mathrm{x}$ & $\mathrm{x}$ & $\mathrm{x}$ & $\mathrm{x}$ & $\mathrm{x}$ & $\mathrm{x}$ \\
\hline Síndrome de Rett & & & $\mathrm{x}$ & $\mathrm{x}$ & $\mathrm{x}$ & $\mathrm{x}$ & $\mathrm{x}$ & $\mathrm{x}$ & $\mathrm{x}$ & $\mathrm{x}$ \\
\hline $\begin{array}{l}\text { Altas } \\
\text { habilidades/superdotação }\end{array}$ & $\mathrm{x}$ & $\mathrm{x}$ & $\mathrm{x}$ & $\mathrm{x}$ & $\mathrm{x}$ & $\mathrm{x}$ & $\mathrm{x}$ & $\mathrm{x}$ & $\mathrm{x}$ & $\mathrm{x}$ \\
\hline
\end{tabular}

Fonte: Elaboração das autoras, com base no de instruções do censo da educação básica (2007 a 2016).

No trabalho específico com o banco de dados de matrículas, uma dificuldade encontrada é a oscilação e mudança constante nas variáveis consideradas nos dados do censo escolar, como as categorias de deficiência. Nos anos de 2007 e 2008, por exemplo, a síndrome de Down 
aparece separada da deficiência mental, porém, nos anos seguintes, o número de matrículas de alunos com síndrome de $\operatorname{Down}^{\mathrm{xix}}$ pode estar somado às demais matrículas de deficiência intelectual ou não.

A fidedignidade das informações depende de todo o processo de construção do banco de dados: começa no preenchimento, transcorre pela coleta, leitura, organização, interpretação e análise dos dados. Considera-se indispensável a reflexão sobre o cuidado de todas essas fases para evitar inferências equivocadas como, por exemplo, a baixa visão, que pode estar relacionada apenas ao uso de óculos. Nesse direcionamento, Meletti e Bueno (2010), ao tratar de estudos com indicadores educacionais, enfatizam que:

Os números apresentados revelam, uma vez mais, a limitação metodológica, haja vista a grande possibilidade, por exemplo, de pessoas com problemas visuais que não se enquadram na condição de deficiência visual, terem se declarado como tais. O mesmo ocorre com os outros tipos de deficiência (MELETTI; BUENO, 2010, p. 7).

Segundo a Nota Técnica $n^{\circ}$ 4/2014 não é necessária a apresentação de documentos clínicos comprobatórios (laudo médico/diagnóstico clínico) para informar no sistema Educacenso o aluno da educação especial. "Por isso, não se trata de documento obrigatório, mas, complementar, quando a escola julgar necessário. O importante é que o direito das pessoas com deficiência à educação não poderá ser cerceado pela exigência de laudo médico" (BRASIL, 2014, p. 3).

Constata-se uma linha tênue entre a amplitude na definição de público-alvo da educação especial e a complexidade conceitual. De um lado, corre-se o risco de estigmatização por rotular desnecessariamente determinado alunado e, de outro, por "negligenciar" uma especificação com laudo, que possibilita uma série de atendimentos e adaptações que contribuem para o desenvolvimento global desses alunos (DIAS, 2014).

\footnotetext{
Assim, se a amplitude do alunado da educação especial pode gerar o risco da inclusão de alunos sem qualquer evidência de prejuízos intrínsecos no âmbito da educação especial, a sua restrição à incorporação pelos sistemas regulares também pode produzir uma massa de mal escolarizados (BUENO; MELETTI, 2011).
}

Ao refletir sobre a identificação do aluno público-alvo da educação especial nos âmbitos educacionais corre-se o risco, se não houver uma formação crítica e consciente dos professores e gestão escolar, de focar no estigma. Segundo Amaral (1995), o estigma se constitui na presença do desconhecido, de uma atribuição de sentido sobre alguém de forma equivocada, e nesta lógica isto pode impactar na área e nas formas de trabalhar com esses alunos.

Acreditamos que alguém com estigma não seja completamente humano. Com base nisso, fazemos vários tipos de discriminações, através das quais efetivamente, e muitas vezes sem pensar, reduzimos suas chances de vida. Construímos uma teoria

\begin{tabular}{l|c|c|c|c|c|c|} 
(C) Rev. Educ. Perspec. & Viçosa, $M G$ & v.8 & n.3 & p.444-461 & set./dez. 2017 & eISSN 2178-8359 \\
\hline
\end{tabular}


do estigma, uma ideologia para explicar a sua inferioridade e dar conta do perigo que ela representa, racionalizando algumas vezes uma animosidade baseada em outras diferenças, tais como as de classe social (GOFFMAN, 1980, p. 15).

Diante disso, as discussões referentes à área da educação especial devem ser proporcionadas na formação inicial de professores. Entretanto, Garcia (2013, p. 116) questiona se é possível "uma educação especial democrática que fuja das armadilhas de uma perspectiva inclusiva que abre mão da aprendizagem dos alunos, que os generaliza e massifica na forma de propor os serviços e que assume a superficialidade como marca da formação docente?".

A educação especial se constitui paralelamente ao sistema educacional brasileiro, associada à falta de base teórica, carência de debate pedagógico e discussão sobre o trabalho docente (GARCIA, 2013).

Outro aspecto a ser considerado é a política pública de financiamento no âmbito do Fundo de Manutenção e Desenvolvimento da Educação Básica e de Valorização dos Profissionais da Educação (Fundeb) que estabeleceu o duplo cômputo das matrículas de alunos público-alvo da educação especial, favorecendo a relação público - privado, conforme apresenta o Art. $5^{\circ}$ (BRASIL, 2011, s.p.):

A União prestará apoio técnico e financeiro aos sistemas públicos de ensino dos
Estados, Municípios e Distrito Federal, e a instituições comunitárias, confessionais
ou filantrópicas sem fins lucrativos, com a finalidade de ampliar a oferta do
atendimento educacional especializado aos estudantes com deficiência, transtornos
globais do desenvolvimento e altas habilidades ou superdotação, matriculados na
rede pública de ensino regular.

Essa política pública de financiamento incide sobre os dados quantitativos do censo escolar, com a duplicidade da matrícula na área da educação especial. Por exemplo, o aluno da educação especial pode matricular-se no ensino regular e, concomitantemente, na instituição especial, para frequentar o atendimento educacional especializado.

Ao analisarem-se os dados referentes à modalidade de educação especial, apresentados nos microdados da educação básica, verificou-se uma lacuna, uma vez que não há separabilidade entre os dados de classe especial e de instituição especial. Por conta dessa lacuna, Santos (2016) buscou a compreensão dos dados de classe especial e de instituição especial no Data Escola Brasil ${ }^{\mathrm{xx}}$ e verificou que, aproximadamente, $45 \%$ das escolas que ofertam serviços nessa modalidade possuem classe especial, enquanto $46 \%$ eram instituições especiais. Observa-se que isso é uma forma de camuflar os altos índices de alunos em espaços segregados, visto que as atuais políticas defendem o ensino no sistema regular.

O estudo sobre os indicadores educacionais pode ser um ponto de partida para os questionamentos existentes e não deve se restringir ao acesso das matrículas dos alunos

\begin{tabular}{l|c|c|c|c|c|c|} 
() Rev. Educ. Perspec. & Viçosa, $M G$ & v.8 & n.3 & p.444-461 & set./dez. 2017 & eISSN 2178-8359 \\
\hline
\end{tabular}


público-alvo da educação especial à escola. Há diversas possibilidades de cruzamento dos microdados do censo escolar, por isso o problema de pesquisa deve estar claro, com foco de coleta e com análises pautadas em referenciais teóricos.

\section{CONSIDERAÇÕES FINAIS}

As questões discutidas sobre os indicadores educacionais não pretenderam acusar ou questionar a seriedade e envolvimento de seus mantenedores na coleta dos dados, ao contrário, buscaram refletir sobre as lacunas e dificuldades ainda existentes, contribuindo para que esses instrumentos possam estar em constante aperfeiçoamento e para a consequente melhora na disponibilização e na fidedignidade dos processamentos, por se constituírem como dados oficiais, em âmbito nacional.

Ao refletir-se sobre os indicadores educacionais brasileiros, deve-se compreender que seus limites se encontram no modo como eles são utilizados pela ordem neoliberal vigente, pois a construção desses dados é de interesse dos organismos internacionais, uma vez que tais informações servem de suporte para o acompanhamento das metas e programas desses organismos. No entanto, a virtude desses dados é possibilidade de explicitação da realidade social, propiciando, para a área científica, ferramentas de análise crítica sobre a configuração educacional do país. É por meio da compreensão dessa realidade, a partir de respaldo teórico, que é possível discutir e vislumbrar melhorias na educação brasileira.

Considera-se que assuntos da área da educação especial precisam estar vinculados à formação inicial docente, de licenciandos e pedagogos, favorecendo o conhecimento a respeito dos alunos da educação especial e de práticas pedagógicas que auxiliem no processo de ensino e aprendizado do currículo escolar. Além disso, o entendimento da área da educação especial poderá incidir no preenchimento do formulário do censo escolar nas escolas brasileiras.

Por fim, os indicadores educacionais não se restringem ao uso do quantitativo voltado para o financiamento e para as políticas públicas. Esses dados podem ser investigados como uma realidade concreta da educação brasileira e favorecer a luta pela educação, no sentido de apropriação dos conhecimentos científicos.

\section{REFERÊNCIAS}

AMARAL, Lígia Assumpção. Conhecendo a deficiência: em companhia de Hércules. São Paulo: Robe Editorial, 1995.

BRASIL. Lei no 9.394, de 20 de dezembro de 1996. Estabelece as Diretrizes e Bases da Educação Nacional. 1996.

\begin{tabular}{l|l|l|l|l|l|l} 
(C) Rev. Educ. Perspec. & Viçosa, $M G$ & v.8 & n.3 & p.444-461 & set./dez. 2017 & eISSN 2178-8359 \\
\hline
\end{tabular}


BRASIL. Ministério da Educação. Política Nacional de Educação Especial na Perspectiva da Educação Inclusiva. Brasília: MEC, 2008. Disponível em: 〈http://www.mec.gov.br>. Acesso em: 12 abr. 2016.

BRASIL. Decreto no 7.611, de 17 novembro de 2011. Dispõe sobre a educação especial, o atendimento educacional especializado e dá outras providências. 2011. Disponível em: <http://www.planalto.gov.br>. Acesso em: 07 abr. 2016.

BRASIL. Lei no 13.005, de 25 de junho de 2014. Aprova o Plano Nacional de Educação, e outras providências. 2014. Disponível em: <http://www.planalto.gov.br>. Acesso em: 13 maio 2016.

BRASIL. Nota Técnica n. 04. MEC/SECADI/DPEE. Orientação quanto a documentos comprobatórios de alunos com deficiência, transtornos globais do desenvolvimento e altas habilidades/superdotação no Censo Escolar, 2014. Disponível em:

<portal.mec.gov.br/index.php?option=com_docman\&task>. Acesso em: 01 nov. 2017.

BRASIL. Ministério da Educação e Cultura. Portaria n. 316 de 4 de abril de 2007.

Disponível em: 〈http:// www.educacao.al.gov.br〉. Acesso em: 04 ago. 2016.

BRASIL. Instituto Nacional de Estudos e Pesquisas Educacionais Anísio Teixeira. Censo Escolar da Educação Básica - Caderno de Instrução, 2007. Disponível em:

<http://portal.inep.gov.br/basica-censo-escolar-questionarios〉. Acesso em: 03 maio 2016.

BRASIL. Instituto Nacional de Estudos e Pesquisas Educacionais Anísio Teixeira. Censo Escolar da Educação Básica - Caderno de Instrução, 2008. Disponível em:

<http://portal.inep.gov.br/basica-censo-escolar-questionarios>. Acesso em: 04 maio 2016.

BRASIL. Instituto Nacional de Estudos e Pesquisas Educacionais Anísio Teixeira. Censo Escolar da Educação Básica - Caderno de Instrução, 2009. Disponível em:

<http://portal.inep.gov.br/basica-censo-escolar-questionarios>. Acesso em: 07 maio 2016.

BRASIL. Instituto Nacional de Estudos e Pesquisas Educacionais Anísio Teixeira. Censo Escolar da Educação Básica - Caderno de Instrução, 2010. Disponível em:

<http://portal.inep.gov.br/basica-censo-escolar-questionarios>. Acesso em: 10 maio 2016.

BRASIL. Instituto Nacional de Estudos e Pesquisas Educacionais Anísio Teixeira. Censo Escolar da Educação Básica - Caderno de Instrução, 2011. Disponível em:

<http://portal.inep.gov.br/basica-censo-escolar-questionarios>. Acesso em: 11 maio 2016.

BRASIL. Instituto Nacional de Estudos e Pesquisas Educacionais Anísio Teixeira. Censo Escolar da Educação Básica - Caderno de Instrução, 2012. Disponível em:

<http://portal.inep.gov.br/basica-censo-escolar-questionarios>. Acesso em: 11 maio 2016.

BRASIL. Instituto Nacional de Estudos e Pesquisas Educacionais Anísio Teixeira. Censo Escolar da Educação Básica - Caderno de Instrução, 2013. Disponível em:

<http://portal.inep.gov.br/basica-censo-escolar-questionarios>. Acesso em: 03 jun. 2016.

\begin{tabular}{l|c|c|c|c|c|c|} 
(C) Rev. Educ. Perspec. & Viçosa, $M G$ & v.8 & n.3 & p.444-461 & set./dez. 2017 & eISSN 2178-8359 \\
\hline
\end{tabular}


BRASIL. Instituto Nacional de Estudos e Pesquisas Educacionais Anísio Teixeira. Censo Escolar da Educação Básica - Caderno de Instrução, 2014. Disponível em:

<http://portal.inep.gov.br/basica-censo-escolar-questionarios〉. Acesso em: 10 jun. 2016.

BRASIL. Instituto Nacional de Estudos e Pesquisas Educacionais Anísio Teixeira. Censo Escolar da Educação Básica - Caderno de Instrução, 2015. Disponível em:

<http://portal.inep.gov.br/basica-censo-escolar-questionarios>. Acesso em: 11 jun. 2016.

BRASIL. Instituto Nacional de Estudos e Pesquisas Educacionais Anísio Teixeira. Censo Escolar da Educação Básica - Caderno de Instrução, 2016. Disponível em:

<http://portal.inep.gov.br/basica-censo-escolar-questionarios>. Acesso em: 03 ago. 2016.

BUENO, José Geraldo Silveira. Educação especial brasileira: integração/ segregação do aluno diferente. São Paulo: Educ, 1993.

BUENO, José Geraldo Silveira; MELETTI, Silvia Márcia Ferreira. Educação infantil e educação especial: uma análise dos indicadores educacionais brasileiros. Contrapontos (Online), v. 11, p. 65-80, 2011.

CASTRO, Maria Helena Guimarães de. Sistemas Nacionais de avaliação e de informações educacionais. 2000. Revista São Paulo em Perspectiva. v. 14, n. 1, São Paulo, jan./mar. 2000. Disponível em: <http://www.scielo.br/scielo.php?script=sci_arttext\&pid=S010288392000000100014>. Acesso em: 05 jul. 2016.

CORRÊA, Nesdete Mesquita. A educação especial no Brasil dos anos 1990: um esboço de política pública no contexto da reforma do Estado. In: 27 ${ }^{\mathbf{a}}$ Reunião da Associação Nacional de Pós-Graduação e Pesquisa em Educação - ANPED, 2004, Caxambu. Sociedade, Democracia e Educação: Qual Universidade? v. 1, p. 1-6, 2004.

DIAS, Edmundo Fernandes. Política como construção de hegemonia. In: DIAS, Edmundo Fernandes. Revolução passiva e modo de vida: ensaios sobre as classes subalternas, o capitalismo e a hegemonia. São Paulo. Sundernann, 2012.

DIAS, Patrícia Jovino de Oliveira. O registro de dados sobre alunos com necessidades educacionais especiais no Censo Escolar da Educação Básica na rede municipal de ensino de Londrina/PR. 2014. 134f. Dissertação (Mestrado em Educação) - Universidade Estadual de Londrina, Londrina, 2014.

EVANGELISTA, Olinda; SHIROMA, Eneida. O. O combate à pobreza nas políticas educativas do século XXI. III Congresso Luso-afro-brasileiro de Ciências Sociais. Coimbra, 2004.

FERRARO, Alceu Ravanello. Quantidade e qualidade na pesquisa em educação na perspectiva da dialética marxista. Pro-Posições (UNICAMP. Impresso), 2012.

\begin{tabular}{l|c|c|c|c|c|c} 
(C) Rev. Educ. Perspec. & Viçosa, $M G$ & v.8 & n.3 & p.444-461 & set./dez. 2017 & eISSN 2178-8359 \\
\hline
\end{tabular}


FERRARO, Alceu Ravanello. Analfabetismo e níveis de letramento no Brasil: o que dizem os Censos? Educação e Sociedade, Campinas, v. 23, n. 81, p. 21-47, dez. 2002. Disponível em: <http://www.cedes.unicamp.br>. Acesso em: 05 jul. 2016.

GARCIA, Rosalba Maria Cardoso. Política de educação especial na perspectiva inclusiva e a formação docente no Brasil. Revista Brasileira de Educação (Impresso), v. 18, p. 101-119, 2013.

GATTI, Bernadete. A. Estudos quantitativos em educação. Educação e Pesquisa, São Paulo, v. 30, p. 11-30, 2004.

GOFFMAN, Erving. Estigma: Notas sobre a Manipulação da Identidade deteriorada. Brasil, Zahar Editores, 1980.

INSTITUTO BRASILEIRO DE GEOGRAFIA E ESTATÍSTICA (IBGE). Brasília, 2015. Disponível em:

<http://www.ibge.gov.br/home/estatistica/populacao/condicaodevida/indicadoresminimos/sin teseindicsociais2015>. Acesso em: 5 de ago. 2016.

JANNUZZI, Gilberta Martino. A educação do deficiente no Brasil: dos primórdios ao início do século XXI. 2. ed. Campinas, São Paulo: Autores Associados, 2006.

JANNUZZI, Paulo Martino. Indicadores para diagnóstico, monitoramento e avaliação de programas sociais no Brasil. Revista do Serviço Público, Brasília, v. 56, n. 2, p. 137-159, 2005.

JANNUZZI, Paulo Martino. Considerações sobre o uso, mau uso e abuso dos indicadores sociais na formulação e avaliação de políticas públicas municipais. Revista Administração Pública. v. 36, n. 1, p. 51-72, 2002. Disponível em:

<http://bibliotecadigital.fgv.br/ojs/index.php/rap/article/viewArticle/6427>. Acesso em: 05 jul. 2016.

KASSAR, Mônica Carvalho Magalhães. Uma breve história da educação das pessoas com deficiências no Brasil. In: MELETTI, Silvia Márcia Ferreira; KASSAR, Mônica de Carvalho Magalhães (Orgs.). Escolarização de alunos com deficiências: desafios e possibilidades. 1. ed. Campinas: Mercado de Letras, v. 1, p. 33-76, 2013.

LEHER. Roberto. Um novo senhor da educação? A política educacional do Banco Mundial para a periferia do capitalismo. Revista Outubro, p. 19-30, 1999.

MELETTI, Silvia Márcia Ferreira; RIBEIRO, Karen. Indicadores educacionais sobre a educação especial no Brasil. Cadernos CEDES, Campinas, v. 34, n. 93, p. 175-189, 2014.

MELETTI, Silvia Márcia Ferreira; BUENO, José Silveira Bueno. Escolarização de alunos com deficiência: uma análise dos indicadores sociais no Brasil (1997-2006). In: Encontro 
Interinstitucional de Pesquisa: políticas públicas e escolarização de alunos com deficiência. 2010, Londrina. Anais Encontro Interinstitucional de Pesquisa. Londrina, p. 01-18, 2010.

ROSEMBERG. Fúlvia. Educação formal, mulher e gênero no Brasil contemporâneo. Revista Estudos Feministas, ano 9, p. 15-540, 2001.

SANFELICE, José Luís. Da pedagogia colonial à educação mercantilista. In: AZEVEDO, Maria José de; DIAS, Romualdo (Org.). Educação e diálogo - Encontros com educadores de Várzea Paulista. 1. ed. Jaboticabal: Editora da Funep, v. 1, p. 93-111, 2011.

SANTOS, Natália Gomes. Os indicadores educacionais das instituições especiais no Brasil: a manutenção dos serviços segregados na Educação Especial. 134f. Dissertação (Mestrado em Educação) - Universidade Estadual de Londrina. Londrina, 2016.

SAVIANI, Dermeval. Escola e democracia. 41. ed. Campinas: Autores Associados, 2009.

UNESCO. Educação para todos. Disponível em:

<http://www.unesco.org/new/pt/brasilia/education/education-for-all>. Acesso em: 08. ago. 2016.

WILLIAMS, Raymond. Base e superestrutura na teoria da cultura marxista. In: WILLIAMS, Raymond. Cultura e Materialismo. Trad. André Glaser - São Paulo: Editora UNESP, 2011.

\section{NOTAS}

\footnotetext{
${ }^{\mathrm{i}}$ Disponível em:<http://portal.inep.gov.br/web/guest/estatisticas-educacionais>. Acesso em: 01 nov. 2017.

ii Disponível em: <http://inep.gov.br/microdados〉. Acesso em: 01 nov. 2017.

iii Informações disponíveis em:

<http://www.ibge.gov.br/home/disseminacao/eventos/missao/carta_servicos_cidadao.shtm.>. Acesso em: 10 jun. 2016.

iv É uma autarquia federal vinculada ao Ministério da Educação (MEC), cuja missão é promover estudos, pesquisas e avaliações sobre o sistema educacional brasileiro, com o objetivo de subsidiar a formulação e implementação de políticas públicas para a área educacional, a partir de parâmetros de qualidade e equidade, bem como de produzir informações claras e confiáveis aos gestores, pesquisadores, educadores e público em geral. Informações disponíveis em: 〈http://portal.inep.gov.br/conheca-o-inep〉. Acesso em: 26 jun. 2016.

${ }^{\mathrm{v}}$ Ensino regular, educação especial e Educação de Jovens e Adultos (EJA).

vi Informações do site do Inep. Disponível em: <http://portal.inep.gov.br/web/educacenso/censo-escolar>. Acesso em: 30 jul. 2016.

vii Disponível em:<www.dataescolabrasil.inep.gov.br> Acesso em: 30 jul. 2016.

viii Disponível em: <http://portal.inep.gov.br/basica-censo-escolar-sinopse-sinopse> Acesso em: 30 jul. 2016.

${ }^{\text {ix }}$ Disponível em: <http://portal.inep.gov.br/basica-levantamentos-microdados> Acesso em: 30 jul. 2016.

${ }^{\mathrm{x}}$ Informações do site do Inep. Disponível em: <http://portal.inep.gov.br/painel-educacional> Acesso em: 30 jul. 2016.

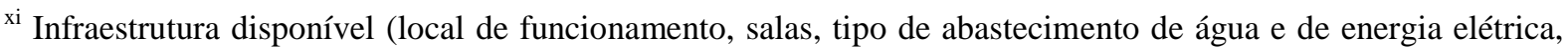
destinação de lixo e esgoto sanitário), dependências existentes (diretoria, secretaria, cozinha, tipo de banheiro, laboratórios, acessibilidade, quadra de esporte, parque infantil), equipamentos (computadores, acesso à internet,
}

\begin{tabular}{l|c|c|c|c|c|c} 
(C) Rev. Educ. Perspec. & Viçosa, $M G$ & v.8 & n.3 & p.444-461 & set./dez. 2017 & eISSN 2178-8359
\end{tabular}


aparelhos de TV e DVD, antena parabólica), etapas e modalidades de escolarização oferecidas, organização do ensino fundamental, localização, dependência administrativa, mantenedora e tipo de escola privada, escolas privadas conveniadas com o poder público. Informações do site do Inep. Disponível em: <http://portal.inep.gov.br/web/educacenso/censo-escolar>. Acesso em: 30 jul. 2016.

${ }^{\text {xii }}$ Sexo, cor/raça, idade, nacionalidade, local de nascimento, turma que frequenta, etapa e modalidade de ensino que frequenta, utilização de transporte escolar, tipo de deficiência. Informações do site do Inep. Disponível em: <http://portal.inep.gov.br/web/educacenso/censo-escolar>. Acesso em: 01 ago. 2016.

xiii São coletadas informações dos professores/as, auxiliares/assistentes educacionais, profissionais/monitores de atividade complementar e tradutores/intérpretes de Libras. Das informações coletadas, pode-se ressaltar: sexo, cor/raça, idade, escolaridade (formação: nível e curso, instituição formadora), etapa e modalidade de ensino de exercício, turma de exercício, disciplinas que ministra, nacionalidade e função que exerce. Informações do site do Inep. Disponível em: 〈http://portal.inep.gov.br/web/educacenso/censo-escolar〉. Acesso em: 02 ago. 2016.

xiv Tipo de atendimento (escolarização, atividade complementar, classe hospitalar, unidade de atendimento socioeducativo, unidade prisional, Atendimento Educacional Especializado - AEE), horários de início e de término, modalidade, etapa, disciplinas, dentre outras. Informações do site do Inep. Disponível em: <http://portal.inep.gov.br/web/educacenso/censo-escolar>. Acesso em: 30 jul. 2016.

${ }^{\mathrm{xv}}$ Informações disponíveis no site: <http://portal.inep.gov.br/o-que-e1〉. Acesso em: 10 ago. 2016.

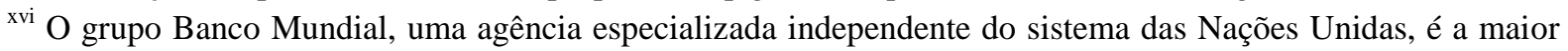
fonte global de assistência para o desenvolvimento, proporcionando cerca de US\$ 60 bilhões anuais em empréstimos e doações aos 187 países-membros. Disponível em: <https://nacoesunidas.org/agencia/bancomundial/>. Acesso em: 09 ago. 2016.

xvii Segundo Saviani (2009) há uma tendência do aligeiramento do ensino destinado às camadas populares.

xviii Alunos com deficiência, transtornos globais do desenvolvimento e altas habilidades/superdotação.

${ }^{\text {xix }}$ Geralmente as pessoas com Síndrome de Down apresentam deficiência intelectual, mas podem apresentar também outras deficiências, algum tipo de transtorno global do desenvolvimento e altas habilidades/superdotação. Sendo assim, deve ser informado ao Censo o tipo de deficiência e não a origem dela. $\mathrm{Na}$ inexistência da deficiência, nenhuma opção deverá ser informada. Informações disponíveis em: <http://download.inep.gov.br/educacao_basica/educacenso/educacao_especial/2014/perguntas_frequentes_ed_e special.pdf>. Acesso em: 01 nov. 2017.

${ }^{\mathrm{xx}}$ Banco online derivado dos microdados da educação básica Inep. Os dados disponibilizados se referem ao banco de escola.

\section{Sobre os Autores}

${ }^{1}$ Taísa Grasiela Gomes Liduenha Gonçalves: Doutorado em Educação Especial (UFSCar) e professora da Faculdade de Educação $(\mathrm{FaE}) /$ Departamento de Ciências Aplicadas à Educação (DECAE) da Universidade Federal de Minas Gerais (UFMG). E-mail: taisaliduenha@gmail.com

${ }^{2}$ Stela Cezare do Santo: E-mail: Graduada em Educação Especial pela Universidade Federal de São Carlos (UFSCar). Docente especialista na Rede Estadual de Ensino de São Paulo, na área de deficiência visual. E-mail: stela_cezare@ hotmail.com

${ }^{3}$ Natália Gomes dos Santos: Doutoranda em Educação pela Universidade Estadual de Londrina (UEL). Docente da graduação em Pedagogia na Universidade Norte do Paraná (Unopar).E-mail: nataliagomes433@gmail.com

\begin{tabular}{l|c|c|c|c|c|c|} 
(C) Rev. Educ. Perspec. & Viçosa, $M G$ & v.8 & n.3 & p.444-461 & set./dez. 2017 & eISSN 2178-8359 \\
\hline
\end{tabular}

